\title{
The impact of human papillomavirus (HPV) status on functional outcomes and quality of life (QOL) after surgical treatment of oropharyngeal carcinoma with free-flap reconstruction
}

Hani Z. Marzouki ${ }^{1 *}$ (D), Vincent L. Biron², Peter T. Dziegielewski ${ }^{1,3}$, Andrew Ma², Jason Vaz ${ }^{2}$ Gabriela Constantinescu², Jeffrey Harris ${ }^{2}$, Daniel $\mathrm{O}^{\prime}$ Connell ${ }^{2}$ and Hadi Seikaly ${ }^{2}$

\begin{abstract}
Background: To determine the impact of Human Papillomavirus (HPV) status on speech, swallowing, and quality of life (QOL) outcomes after surgical treatment of oropharyngeal cancer (OPSCC).

Methods: A retrospective review of a prospectively collected database of all patients with OPSCC diagnosed and treated from 1998 to 2009. Speech, swallowing, and quality of life data were gathered at 3 different evaluation points. HPV status was determined using p16 positivity as a surrogate marker. Univariate and multivariate statistical analyses were performed to identify whether p16 status is a significant predictor of functional outcome and QOL.

Results: One hundred twelve patients with OPSCC and known p16 status were treated with primary surgery between 1998 and 2009, with mean age of 56 years. Out of those patients 63 (56\%) were p16 positive. Speech intelligibility remained high at 1-year post operation (95.4\%). Only $11.5 \%$ of the patients required a feeding tube at 1 year after surgery to maintain their daily caloric requirements and the risk of aspiration after surgery was not significant $(p=0.097)$. There was no statistically or clinically significant difference in speech, swallowing ability, swallowing safety and QOL outcomes between p16-positive and negative OPSCC.
\end{abstract}

Conclusions: Surgically treated OPSCC patients demonstrate excellent swallowing function and can achieve excellent speech perception. P16 status may not be predictive of functional outcomes or QOL in surgically treated OPSCC.

\footnotetext{
* Correspondence: hanimarzouki@gmail.com

${ }^{1}$ Department of Otolaryngology-Head and Neck Surgery, King Abdulaziz

University, Jeddah, Saudi Arabia

Full list of author information is available at the end of the article
}

(c) The Author(s). 2018 Open Access This article is distributed under the terms of the Creative Commons Attribution 4.0 International License (http://creativecommons.org/licenses/by/4.0/), which permits unrestricted use, distribution, and reproduction in any medium, provided you give appropriate credit to the original author(s) and the source, provide a link to the Creative Commons license, and indicate if changes were made. The Creative Commons Public Domain Dedication waiver (http://creativecommons.org/publicdomain/zero/1.0/) applies to the data made available in this article, unless otherwise stated. 


\section{Background}

Traditionally, tobacco and alcohol use have subscribed to be the primary risk factors for oropharyngeal squamous cell carcinoma (OPSCC). However, the past decade has seen a rapid increase in the incidence of human papillomavirus (HPV) related oropharyngeal cancers in developing countries [1-4]. Molecular and epidemiologic studies suggest that HPV-positive oropharyngeal cancers comprise a distinct disease entity that has a higher survival and better response to treatment [5-8]. Although survival is the fundamental goal in treating oropharyngeal cancer patients, their functional and quality of life (QOL) outcomes are becoming a primary concern of the patients and their health care providers. The issue of these outcomes after surgical treatment has received considerable critical attention.

The optimal treatment of advanced stage OPSCC has been a subject of debate for several years. In population based studies, the 5-year survival of oropharyngeal cancer patients has been shown to be better when treated with primary surgical resection compared to primary radiation treatment [9-12]. Tschiesner et al. (2012) investigated the functional and quality of life outcomes between primary radiation and major surgical resection with free flap reconstruction in advanced head and neck cancer patients and found no significant difference [13]. The past decade has seen a significant paradigm shift toward surgical treatment of OPSCC coinciding with the introduction of less invasive transoral approaches $[14,15]$. Studies have reported excellent functions and quality of life after transoral surgery for oropharyngeal cancer patients [15-17]. In previous studies conducted by our group we have found that surgically treated oral and oropharyngeal cancer patients have excellent functional outcomes including speech intelligibility and safe efficient swallowing [18-21] but this was not investigated in relation to $\mathrm{HPV} / \mathrm{p} 16$ status. Several studies have reported improved survival outcomes with HPV positive vs. negative OPSCC but there is a paucity of knowledge regarding the role of HPV positivity on functional outcomes and quality of life, particularly in surgically treated patients.

The aim of this study is to determine the impact of the p16 status on speech, swallowing and QOL outcomes in OPSCC patients treated with primary surgery.

\section{Methods}

Prior to commencing the study, ethical clearance was sought from the University of Alberta Health Research and Ethics Board.

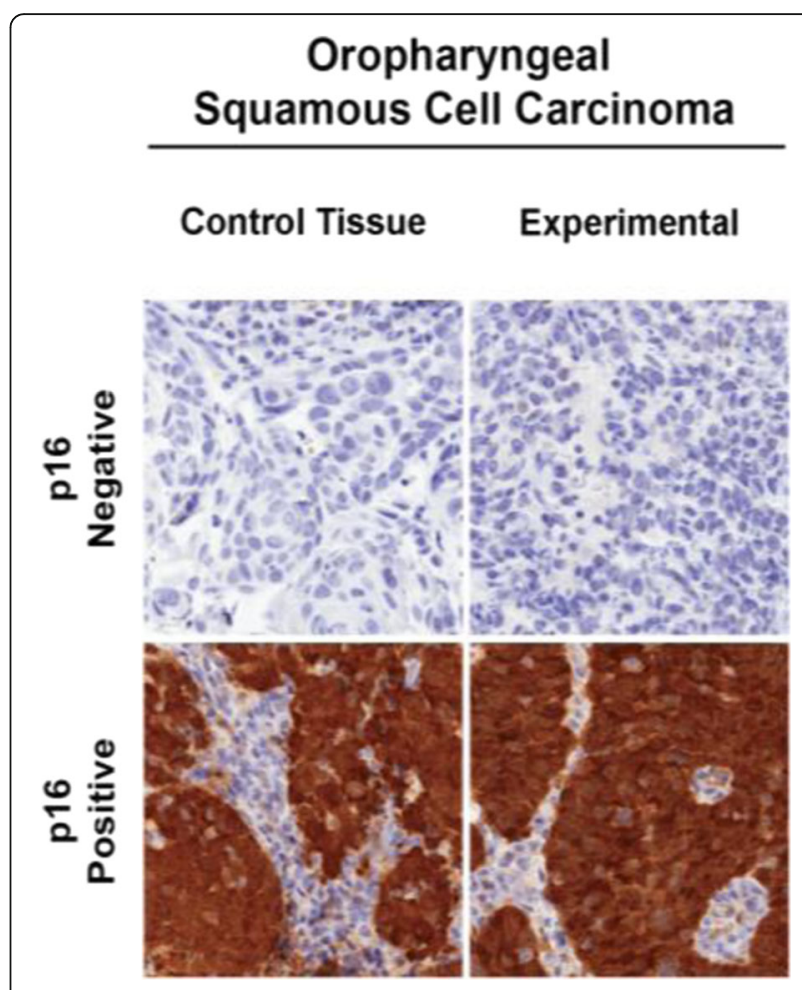

Fig. 1 Histopathologic slide showing P16 positivity

\section{Study design and patients}

The study involved a retrospective review of a prospectively collected outcomes dataset. The initial sample consisted of 226 patients with OPSCC, treated and followed in the University of Alberta Hospital from 1998 to 2009. All of these patients were treated with major resection and free flap reconstruction. As part of our standard care, patients are assessed at the visit the Institute for Reconstructive Sciences in Medicine (iRSM) at the Misericordia Hospital in Edmonton, Alberta, Canada; at 3 different times for speech, swallowing and QOL assessments with a speech-language pathologist. A retrospective chart review of these patients was completed to determine the following parameters: age, gender, risk

Table 1 Demographics and clinical characteristics

\begin{tabular}{ll}
\hline Characteristic & No. (\%) \\
\hline$N$ & 112 \\
Age (yrs) & 56 \\
Gender & \\
$\quad$ Male & $92(82 \%)$ \\
$\quad$ Female & $20(18 \%)$ \\
p16 status & \\
P16 Positive $(+)$ & $63(56 \%)$ \\
P16 Negative $(-)$ & $49(44 \%)$ \\
\hline
\end{tabular}


Table 2 Primary Tumor Stages

\begin{tabular}{llllllll}
\hline & N0 & N1 & N2a & N2b & N2c & N3 & TOTAL \\
\hline T1 & $1(1 \%)$ & $2(2 \%)$ & $4(3.5 \%)$ & $2(2 \%)$ & $0(0 \%)$ & $11(10 \%)$ \\
T2 & $1(1 \%)$ & $5(4.5 \%)$ & $7(6.25 \%)$ & $10(9 \%)$ & $2(2 \%)$ & $5(4.5 \%)$ & $30(27 \%)$ \\
T3 & $13(12 \%)$ & $6(5.4 \%)$ & $7(6.25 \%)$ & $18(16 \%)$ & $3(2.7 \%)$ & $2(2 \%)$ & $49(44 \%)$ \\
T4 & $1(1 \%)$ & $5(4.5 \%)$ & $3(2.7 \%)$ & $5(4.5 \%)$ & $7(6.25 \%)$ & $1(1 \%)$ & $22(19 \%)$ \\
TOTAL & $16(14 \%)$ & $18(16 \%)$ & $21(19 \%)$ & $35(31 \%)$ & $12(11 \%)$ & $10(9 \%)$ & 112 \\
\hline
\end{tabular}

factors, site of lesion, TNM staging and speech, swallowing and QOL data.

\section{Subjects selection and withdrawal Inclusion criteria}

1-. Adult patients ( $>18$ years).

2-. Primary cancer of the oropharynx.

3-. Primary treatment was surgical.

4-. Available speech and swallowing outcomes data.

5-. Available QOL data.

\section{Exclusion criteria}

1-. Patients younger than 18 years.

2-. Head and neck cancer other than the oropharynx.

3-. Treated primarily with radiation therapy.

4-. Speech and swallowing data not available.

5-. QOL data not available.

\section{Functional assessment}

Swallowing and speech functions and QOL were measured and prospectively recorded at 3 points in time: preoperatively, 6 months postoperative; and 1 year postoperative at the.

Head and Neck Surgery Functional Assessment Laboratory at the iRSM [22].

Objective functional outcomes were measured as follows:

\section{Speech assessment}

Single Word Intelligibility (SWI) and Sentence Intelligibility (SI) as determined by Naïve listener were measured using the standard Computerized Assessment of Intelligibility of Dysarthric Speech (CAIDS; Pro-Ed, Austin, TX) [22, 23].

\section{Swallowing assessment}

Swallowing was assessed in terms of ability (gastrostomy tube (g-tube) requirement rate) and safety (risk of aspiration) of swallowing. Swallowing ability was defined as complete independence from a g-tube to maintain their daily caloric requirements. Video Fluoroscopic Swallowing Studies (VFSS), using a standard Penetration-Aspiration Scale [24], were used to evaluate swallowing safety [22, 24] . Patients were divided into two groups according to the Penetration-Aspiration Scale (Aspiration group and No Aspiration group).

\section{Quality of life (QOL) assessment}

QOL was measured using the European Organization for Research and Treatment of Cancer Head \& Neck 35 Quality of Life Questionnaire (EORTC H\&N 35). Subjects were asked to fill out the questionnaire to assess their QOL, which takes 20-30 min each time. Scores were scaled up to a maximum of 100 . Minimal clinically important differences were approximated as described by others [25].

\section{HPV status and P16 immunohistochemistry staining}

Several different methods have been developed and introduced to identify HPV status. To date viral DNA amplification by the Polymerase Chain Reaction (PCR) is still the most sensitive test [26-28]. Immunohistochemistry (IHC) using p16 has been used as a surrogate marker of oncogenic HPV and found to
Table 3 Single word intelligibility

\begin{tabular}{llllll}
\hline Intelligibility & Pre-Op & 6 Mo Post-Op & 12 Mo Post-Op & $\Delta$ & $p$-value \\
\hline All & $94.4 \%$ & $85.5 \%$ & $85 \%$ & $9.4 \%$ & $<0.001$ \\
P16- & $92 \%$ & $85.1 \%$ & $84.8 \%$ & $7.2 \%$ & .003 \\
P16 & $95.7 \%$ & $84.4 \%$ & $85.1 \%$ & $10.6 \%$ & $<0.001$ \\
p-value (p16) & 0.248 & 0.418 & 0.795 & & \\
\hline
\end{tabular}

Table 4 sentence intelligibility

\begin{tabular}{llllll}
\hline Intelligibility & Pre-Op & 6 Mo Post-Op & 12 Mo Post-Op & $\Delta$ & $p$-value \\
\hline Sentence & $98.7 \%$ & $94 \%$ & $95.4 \%$ & $3.3 \%$ & $<0.001$ \\
P16- & $98.2 \%$ & $92.1 \%$ & $94.6 \%$ & $3.6 \%$ & .053 \\
P16+ & $99 \%$ & $95 \%$ & $95.8 \%$ & $3.2 \%$ & $<0.001$ \\
-value (p16) & 0.144 & 0.207 & 0.897 & & \\
\hline
\end{tabular}


Table 5 Single word intelligibility - Multivariable analysis

\begin{tabular}{lll}
\hline Variables & $p$-Value & $95 \%$ confidence interval \\
\hline P16 & 0.22 & $-5.74-13.74$ \\
Increase in AGE & 0.04 & $0.08-0.80$ \\
T Stage & 0.54 & $-12.16-11.89$
\end{tabular}

have a significant concordance rate of more than $80 \%$ with PCR testing and this test is now widely available and accepted as a method of detecting HPV status, and has been used in many investigational studies [3, 10, 29-31]. HPV status of patients in this study was determined by p16 immunohostochemistry of form alin-fixed paraffin embedded (FFPE) tumors as previously reported [10]. Arrays were subjected to both a standard hematoxylin and eosin (H\&E) staining and a p16INK4a mouse monoclonal antibody (p16) (Fig. 1). P16 positivity was digitally determined using AQUAnalysis software (HistoRx, Inc. Branford, Connecticut) as previously described [10-12, 32].

\section{Data analysis}

Data management and analysis was performed using SPSS version 20. A univariate comparison between the groups was made using Mann-Whitney Test for the continuous data and Chi square test for the categorical data. The Wilcoxon non-parametric test was also used to compare the data across the time periods and the Friedman test was used for the statistical analysis of QOL. The mean scores for word and sentence intelligibility were compared using linear regression analysis. A multivariate analysis of the different variables with potential effect on the rate of g-tube requirement was done using a logistic regression analysis. Differences between groups were deemed to be statistically significant with a $p$ value $<0.05$.

\section{Results}

\section{Patient demographics and clinical characteristics}

Table 1 summarizes the demographics and clinical characteristics of the 112 patients that have met the inclusion/exclusion criteria and included in this study. Similar to previous studies, the majority of OPSCC in

Table 6 Sentence intelligibility - Multivariable analysis

\begin{tabular}{lll}
\hline Variables & $P$-Value & 95\% confidence interval \\
\hline P16 & 0.86 & $-3.95-5.29$ \\
Increase in AGE & 0.01 & $0.05-0.39$ \\
T Stage & 0.56 & $-7.58-3.83$ \\
\hline
\end{tabular}

Table 7 Swallowing Ability - The rate of G-Tube requirement

\begin{tabular}{lllll}
\hline & $\begin{array}{l}\text { ALL (\% with } \\
\text { g-tube) }\end{array}$ & $\begin{array}{l}\text { P16- }(\% \text { with } \\
\text { g-tube })\end{array}$ & $\begin{array}{l}\text { P16 }+(\% \text { with } \\
\text { g-tube })\end{array}$ & $\begin{array}{l}\text { HPV+/HPV- } \\
(p \text {-Value })\end{array}$ \\
\hline Pre OP & 2 & 6 & 0 & 0.068 \\
6 M Post OP & 29.6 & 41 & 23 & 0.084 \\
12 M Post OP & 11.5 & 21 & 9 & 0.172 \\
\hline
\end{tabular}

this cohort were relatively young (mean age 56 years), p16 positive males. Most patients also presented with advanced stage disease as according the AJCC 7th edition (Table 2).

\section{Functional outcome results Speech function}

Single word and sentence intelligibilities The results in Tables 3 and 4 showed an $85 \%$ postoperative mean score for word intelligibility. On the other hand, showed an excellent postoperative sentence intelligibility of 95.4\%. Overall, p16 status did not show any statistical significant effect on speech intelligibility.

A Multivariable analysis using linear-regression was used to assess the effect of p16 status, age, stage and the percentage of base of tongue and soft palate resection on intelligibility. This analysis revealed a positive correlation between patients' age and the percentage of base of tongue resection on both single word and sentence intelligibilities with $p$-values less than 0.05 . There were no significant differences in intelligibilities in relation to p16 status (Tables 5 and 6).

\section{Swallowing function}

Swallowing ability Only $13 \%$ of patients required a g-tube 12 -months after surgery to maintain their daily caloric requirements and there was no statistical significant difference in the rate of g-tube dependency in relation to p16 status (Table 7). The results, as shown in Table 8 , indicate that the percentage of base of tongue

Table 8 The rate of G-Tube requirement - Multivariable analysis

\begin{tabular}{ll}
\hline Variables & $P$-Value \\
\hline p16 & 0.23 \\
AGE & 0.9 \\
T Stage & 0.42 \\
\% BOT & 0.01 \\
$\%$ SP & 0.37 \\
\hline
\end{tabular}

Logistic regression analysis

BOT Base of Tongue, SP Soft Palate 
Table 9 Swallowing Safety (the risk (\%) of aspiration

\begin{tabular}{lllll}
\hline & All & P16- & P16+ & $p$-Value \\
\hline Pre OP & $0 \%$ & $0 \%$ & $0 \%$ & \\
6 M Post Op & $11.5 \%$ & $17.4 \%$ & $8 \%$ & 0.26 \\
12 M Post Op & $12 \%$ & $17.6 \%$ & $9.4 \%$ & 0.4 \\
$p$-Value & 0.097 & 0.223 & 0.368 & \\
\hline
\end{tabular}

Using Video Fluoroscopic Swallowing Study (VFSS) to Measure the risk of aspiration according to a standard Penetration-Aspiration Scale

resection has a significant association with the rate of g-tube dependency.

Swallowing safety Overall, swallowing was found to be safe post-operatively and there was no increase in the risk of aspiration was detected in relation to p16 status. None of these differences were statistically significant (Table 9).

\section{Quality of life (QOL) results}

Patients were divided into three groups according to the change in their QOL scores. Change $(\Delta)$ in mean score:

1. Mild $\Delta=5-10$

2. Moderate $\Delta=10-20$

3. Severe $\Delta \geq 20$

What has been considered as clinically significant was mean score difference of more than 10 [33-35].

\section{Overall quality of life}

From this data, we can see that the overall QOL scores postop and preop was excellent (Tables 10 and 11), although the difference was statistically significant, but the differences in the mean scores was not clinically significant $(\Delta$ in mean score $<10)$. Figure 2 presents an overview of the QOL outcomes by time frame and the main QOL domains.

\section{Quality of life (QOL) and p16}

When comparing different domains of QOL and p16 status it was found that p16 positive patients had improved social eating and sexuality compared to p16 negative patients (clinically and statistically significant) (Table 12). There was no clinical significant difference in the overall QOL in relation to p16 status (Table 12).

\section{Discussion}

The current literature suggests that surgical treatment of advanced oropharyngeal cancer is associated with poor QOL and functional outcomes. Results of our study suggest the contrary; these patients achieved excellent swallowing abilities with only $13 \%$ of the patients required G-Tube at 12 months post treatment, which is comparable to patients that underwent TORS [16, 36] and speech perception, with sentence recognition by naïve listeners that was near perfect post-surgery. Although word intelligibility is a sensitive test for speech outcome, it is not clinically important. The results shown in Tables 3 and 4 indicate that the mean score for postoperative word intelligibility dropped on the order of $9 \%$. On the other hand, sentence intelligibility that is more clinically important as it represents listener appreciation of contextual speech showed only a 3\% drop in intelligibility after surgery. Overall, p16 status did not affect Sentence/contextual speech. Contextual speech was still well understood in both p16 positive and p16 negative patients with no significant differences. Advanced stage OPSCC patients treated with primary surgical approaches

Table 10 Quality of Life (QOL) mean Scores

\begin{tabular}{|c|c|c|c|c|c|}
\hline & Pre-Op Mean score (SD) & 6 months Mean score (SD) & 12 months Mean score (SD) & $\Delta$ & $P$ - Value \\
\hline pain & $24(23)$ & $22(17.6)$ & $16(17.3)$ & -8 & 0.02 \\
\hline swallowing & $16(23)$ & $31(22.6)$ & $26(22.2)$ & 10 & $<0.01$ \\
\hline senses & $14(21.2)$ & $26(20.7)$ & $21(23.2)$ & 7 & $<0.01$ \\
\hline speech & $15(18.3)$ & $23(18.7)$ & $22(19.4)$ & 7 & 0.03 \\
\hline social eating & $16(25)$ & $28(22.3)$ & $32(24.3)$ & 16 & $<0.01$ \\
\hline social contact & $5(12.4)$ & $12(18)$ & $11(17.6)$ & 6 & 0.004 \\
\hline sexuality & $16(28)$ & $23(28.1)$ & $18(27.7)$ & 2 & 0.02 \\
\hline teeth & $10(22)$ & $14(21.1)$ & $24(32)$ & 14 & 0.07 \\
\hline mouth open & $20(33)$ & $39(33)$ & $42(36.1)$ & 22 & $<0.01$ \\
\hline coughing & $30(24.1)$ & $40(28)$ & $34(23.7)$ & 4 & 0.03 \\
\hline felt ill & $12(21.3)$ & $15(24)$ & $5(15.5)$ & -7 & 0.002 \\
\hline
\end{tabular}


Table 11 Overall Quality of Life (QOL) Scores

\begin{tabular}{lll}
\hline & $N$ & Mean EORTC H\&N 35 score (SD) \\
\hline Pre-Op & 85 & $19(14.14)$ \\
6 M Post-p & 68 & $32(13.47)$ \\
12 M Post-p & 68 & $27(12.54)$ \\
Change $(\Delta)$ & 17 & $8(p<0.01)$ \\
\hline
\end{tabular}

$\Delta=8(<10)$ not clinically significant

have also been shown to have better survival outcomes, especially those in the high-risk groups (HPV negative and smokers) $[10,37]$. Primary surgery for OPSCC can therefore provide excellent oncologic and functional outcomes.

HPV positive OPSCC is known to have excellent treatment response with high survival rates shown to extend beyond 5 years [38-41]. With the rising population of HPV-OPSCC survivors, investigating the functional outcomes and QOL of these patients is of utmost importance. To date, few studies have reported an association between HPV status and functional outcomes and/or QOL in OPSCC [25]. A study of 177 OPSCC patients $(45 \%$ p16 +) reported higher University of Washington (UW) QOL scores in p16 positive patients pre- and post-treatment [42]. Another study using showed higher pre-treatment UW QOL scores in HPV positive vs negative OPSCC, however this association did not persist beyond 1 year post-treatment [43]. In a multicenter study of 48 patients with OPSCC (39\% HPV+), no significant differences in EORTC QOL surveys between HPV positive and negative patients [44]. When comparing surgical versus non-surgical treatments, these studies did not show any differences in QOL measurements. In a retrospective analysis of OPSCC patients treated with CRT, p16 positive patients had better baseline QOL scores but demonstrated a greater reduction in QOL post-treatment [45]. An independent study comparing TORS and CRT treatments showed that patients treated with primary TORS approaches had significantly better saliva-related QOL [46]. The present study was designed to determine the association of p16 status on the functional outcomes and QOL of surgically treated OPSCC with open surgery and free flap reconstruction that is more. Our patient cohort was unique with a large number of surgically treated
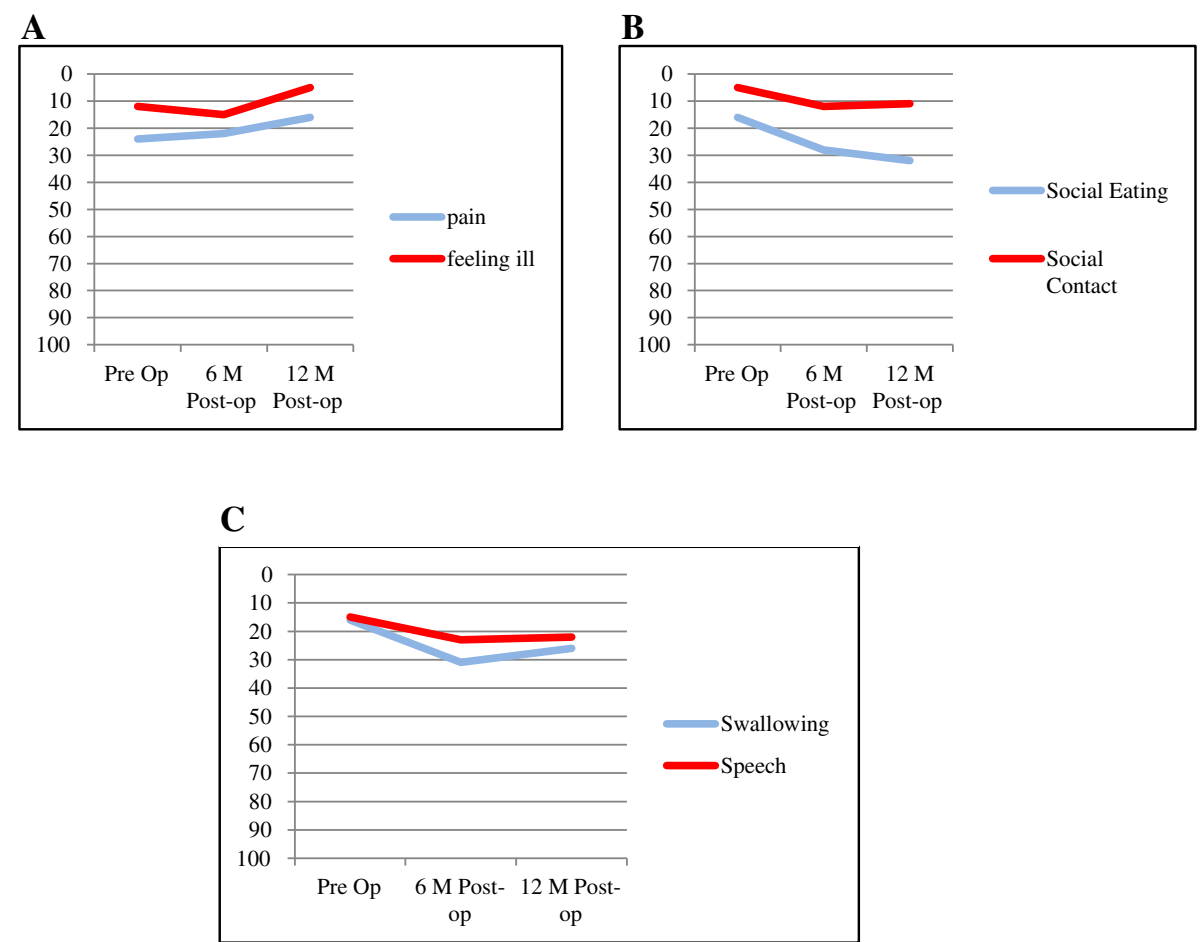

\footnotetext{
A: Pain and feeling ill improved at 12 months post operatively from the base line B: Impairment in social eating and minimal in social contact
}

C: Impairment compared to base line

Fig. 2 Overall Quality of Life (QOL) Domains: a: Pain and feeling ill improved at 12 months post operatively from the base line. b: Impairment in social eating and minimal in social contact. c: Impairment compared to base line 
Table 12 p16 and Quality of Life (QOL) Scores

\begin{tabular}{|c|c|c|c|c|c|}
\hline \multirow{2}{*}{ pain } & & HPV - Mean score (SD) & HPV + Mean score (SD) & $\Delta$ & $P$-Value \\
\hline & & $18(17.34)$ & $16(17.37)$ & -2 & 0.58 \\
\hline swallowing & & $30(24.22)$ & $27(21.33)$ & -3 & 0.63 \\
\hline senses & & $16(19.77)$ & $24(24.54)$ & 8 & 0.24 \\
\hline speech & & $21(17.78)$ & $23(20.42)$ & 2 & 0.75 \\
\hline social eating & & $43(31.53)$ & $26(17.29)$ & -17 & 0.04 \\
\hline social contact & & $11(17.71)$ & $11(17.82)$ & 0 & 0.99 \\
\hline sexuality & & $28(35.87)$ & $16.5(22.69)$ & -11.5 & 0.19 \\
\hline teeth & & $23(32.46)$ & $24(32.1)$ & 1 & 0.84 \\
\hline mouth open & & $45(38.41)$ & $40(35.25)$ & -5 & 0.64 \\
\hline coughing & & $35(23.52)$ & $34(24.09)$ & -1 & 0.89 \\
\hline felt ill & & $1.5(6.95)$ & 7 (18.26) & 5.5 & 0.41 \\
\hline & $\mathbf{N}$ & P16 - Mean score (SD) & P16 + Mean score (SD) & $\Delta$ & P-Value \\
\hline Pre-Op & 82 & $22.5(15.6)$ & $13(12.1)$ & -9.5 & 0.005 \\
\hline 6 M Post-p & 65 & $33.5(16)$ & $29(12)$ & -4.5 & 0.24 \\
\hline 12 M Post-p & 65 & $28.5(10.5)$ & $26(13.4)$ & -2.5 & 0.45 \\
\hline
\end{tabular}

Significant $p$-value are highlited in bold

patients, however similar to other studies, we did not find significant differences between p16 positive and negative OPSCCs. Regardless of p16 status, surgically treated OPSCC patients had excellent QOL, speech and swallowing outcomes.

This study was limited by a lack of reliable tobacco use history available as part of our retrospective analysis. Only surgically treated patients were included in this study and therefore comparisons cannot be made with patients who received CRT or RT alone. In addition, a single instrument was used to measure QOL, however, the EORTC H\&N 35 has been validated and is one of the most widely accepted QOL questionnaires for OPSCC $[25,44,47]$.

\section{Conclusion}

This study suggests that primary surgery for OPSCC results in excellent QOL and functional outcomes that are not associated with p16 status. Further prospective studies comparing surgical and non-surgically treated patients according to HPV/p16 status may be beneficial in predicting and optimizing outcomes.

\footnotetext{
Abbreviations

ACR: Alberta Cancer Registry; BOT: Base of tongue; CRT: Chemoradiation; EORTC: European Organization for Research and Treatment of Cancer; Gtube: Gastrostomy tube; HPV: Human papillomavirus; HPV-OPSCC: Human papillomavirus-related oropharyngeal squamous cell carcinoma; IHC: Immunohistochemistry; iRSM: Institute for Reconstructive Sciences in Medicine; NCCN: National Comprehensive Cancer Network; OPSCC: Oropharyngeal squamous cell carcinoma; PCR: Polymerase chain reaction; QOL: Quality of life; RT: Radiation therapy; SD: Standard deviation; SI: Sentence intelligibility; SP: Soft palate; SWI: Single word intelligibility; VFSS: Video fluoroscopic swallowing study
}

\section{Funding}

Funding for this study was obtained from the Alberta Head and Neck Centre for Oncology and Reconstruction Foundation.

Availability of data and materials

The data that support the findings of this study are available from the Alberta Cancer Registry but restrictions apply to the availability of these data including health ethics approval obtained for the current study, and so are not publicly available.

\section{Authors' contributions}

HZM was involved in all aspects of experimental design, data collection, data analysis and is the primary contributor in manuscript preparation. VLB was involved in data collection, statistical analysis and manuscript preparation. PTD, AM, JV and GC participated in data collection. DAO, JH and HS were involved in data analysis and manuscript preparation. All authors read and approved the final manuscript.

Ethics approval and consent to participate

Ethics approval for this study was obtained from the University of Alberta Health Ethics Research Board protocol (Pro00016426 HREBA.CC-16-0829).

\section{Consent for publication}

Not applicable.

\section{Competing interests}

The authors declare that they have no competing interests.

\section{Publisher's Note}

Springer Nature remains neutral with regard to jurisdictional claims in published maps and institutional affiliations.

\section{Author details}

'Department of Otolaryngology-Head and Neck Surgery, King Abdulaziz University, Jeddah, Saudi Arabia. ${ }^{2}$ Division of Otolaryngology-Head and Neck Surgery, Department of Surgery, University of Alberta and Alberta Health Services, 1E4.34, WMC 8440 - 112 Street, Edmonton, AB T6G 2B7, Canada. ${ }^{3}$ Department of Otolaryngology, University of Florida, Florida, USA. 


\section{Received: 1 February 2018 Accepted: 26 August 2018}

\section{Published online: 19 September 2018}

\section{References}

1. Kreimer AR, Clifford GM, Boyle P, Franceschi S. Human papillomavirus types in head and neck squamous cell carcinomas worldwide: a systematic review. Cancer Epidemiol Prev Biomarkers. 2005;14:467-75.

2. Näsman A, Attner P, Hammarstedt L, Du J, Eriksson M, Giraud G, et al. Incidence of human papillomavirus (HPV) positive tonsillar carcinoma in Stockholm, Sweden: an epidemic of viral-induced carcinoma? Int J Cancer. 2009;125:362-6.

3. Hayes DN, Van Waes C, Seiwert TY. Genetic landscape of human papillomavirus-associated head and neck Cancer and comparison to tobacco-related tumors. J Clin Oncol. 2015;33:3227-34.

4. Gillison ML, Chaturvedi AK, Anderson WF, Fakhry C. Epidemiology of human papillomavirus-positive head and neck squamous cell carcinoma. Proc Am Soc Clin Oncol. 2015;33:3235-42.

5. Lindsay C, Seikaly H, Biron VL. Epigenetics of oropharyngeal squamous cell carcinoma: opportunities for novel chemotherapeutic targets. J Otolaryngol Head Neck Surg. 2017:46:9.

6. Gillison ML, Gillison ML, D'souza G, Westra W, Westra W, et al. Distinct Risk Factor Profiles for Human Papillomavirus Type 16-Positive and Human Papillomavirus Type 16-Negative Head and Neck Cancers. J Natl Cancer Inst. 2008;100:407-20. Available from: http://eutils.ncbi.nlm.nih.gov/entrez/eutils/ elink.fcgi?dbfrom=pubmed\&id $=18334711$ \&retmode $=$ ref\&cmd=prlinks

7. Gillison ML, Shah KV. Human papillomavirus-associated head and neck squamous cell carcinoma: mounting evidence for an etiologic role for human papillomavirus in a subset of head and neck cancers. Curr Opin Oncol. 2001;13:183-8.

8. Lydiatt WM, Patel SG, O'Sullivan B, Brandwein MS, Ridge JA, Migliacci JC, et al. Head and Neck cancers-major changes in the American Joint Committee on cancer eighth edition cancer staging manual. CA Cancer J Clin. 2017;67: 122-37.

9. O'Connell D, Seikaly H, Murphy R, Fung C, Cooper T, Knox A, et al. Primary surgery versus chemoradiotherapy for advanced oropharyngeal cancers: a longitudinal population study. J Otolaryngol Head Neck Surg. 2013;42:31.

10. Seikaly H, Biron VL, Zhang H, O'Connell DA, Côté DWJ, Ansari K, et al. Role of primary surgery in the treatment of advanced oropharyngeal cancer. Head Neck. 2016;38(Suppl 1):E571-9.

11. Cooper T, Biron VL, Adam B, Klimowicz AC, Puttagunta L, Seikaly H. Association of keratinization with 5-year disease-specific survival in oropharyngeal squamous cell carcinoma. JAMA Otolaryngol Head Neck Surg. 2015;141:250-6.

12. Cooper T, Biron V, Adam B, Klimowicz AC, Puttagunta L, Seikaly H. Prognostic utility of basaloid differentiation in oropharyngeal cancer. J Otolaryngol Head Neck Surg. 2013;42:57.

13. Tschiesner U, Schuster $L$, Strieth $S$, Harréus U. Functional outcome in patients with advanced head and neck cancer: surgery and reconstruction with free flaps versus primary radiochemotherapy. Eur Arch Otorhinolaryngol. 2012;269:629-38.

14. Chauhan P, Byrne H, Taylor E, Sheahan P. Oncological and functional outcomes of transoral surgery for the treatment of oropharyngeal cancer. Ir J Med Sci. 2015;184:825-30.

15. Lörincz BB, Busch C-J, Möckelmann N, Knecht R. Feasibility and safety of transoral robotic surgery (TORS) for early hypopharyngeal cancer: a subset analysis of the Hamburg University TORS-trial. Eur Arch Otorhinolaryngol. 2015;272:2993-8

16. Dziegielewski PT, Teknos TN, Durmus K, Old M, Agrawal A, Kakarala K, et al. Transoral robotic surgery for oropharyngeal cancer: long-term quality of life and functional outcomes. JAMA Otolaryngol Head Neck Surg. 2013;139: 1099-108.

17. Biron VL, O'Connell DA, Barber B, Clark JM, Andrews C, Jeffery CC, et al. Transoral robotic surgery with radial forearm free flap reconstruction: case control analysis. J Otolaryngol Head Neck Surg. 2017;46:20.

18. Brown L, Rieger JM, Harris J, Seikaly H. A longitudinal study of functional outcomes after surgical resection and microvascular reconstruction for oral cancer: tongue mobility and swallowing function. J Oral Maxillofac Surg. 2010;68:2690-700

19. Seikaly H, Rieger J, Zalmanowitz J, Tang JL, Alkahtani K, Ansari K, et al. Functional soft palate reconstruction: a comprehensive surgical approach. Head Neck. 2008;30:1615-23.
20. Seikaly H, Rieger J, O'Connell D, Ansari K, Alqahtani K, Harris J. Beavertail modification of the radial forearm free flap in base of tongue reconstruction: technique and functional outcomes. Head Neck. 2009;31: 213-9.

21. O'Connell DA, Rieger J, Harris JR, Dziegielewski P, Zalmanowitz J, Sytsanko $A$, et al. Swallowing function in patients with base of tongue cancers treated with primary surgery and reconstructed with a modified radial forearm free flap. Arch. Otolaryngol. Head Neck Surg. 2008;134:857-64.

22. Rieger JM, Zalmanowitz JG, Li SYY, Sytsanko A, Harris J, Williams D, et al. Functional outcomes after surgical reconstruction of the base of tongue using the radial forearm free flap in patients with oropharyngeal carcinoma. Head Neck. 2007;29:1024-32.

23. Yorkston KM, Beukelman DR. Communication efficiency of dysarthric speakers as measured by sentence intelligibility and speaking rate. J Speech Hear Disord. 1981:46:296-301.

24. Robbins J, Coyle J, Rosenbek J, Roecker E, Wood J. Differentiation of normal and abnormal airway protection during swallowing using the penetrationaspiration scale. Dysphagia. 1999;14:228-32.

25. Høxbroe Michaelsen S, Grønhøj C, Høxbroe Michaelsen J, Friborg J, von Buchwald C. Quality of life in survivors of oropharyngeal cancer: a systematic review and meta-analysis of 1366 patients. Eur J Cancer. 2017;78: 91-102.

26. McKaig RG, Baric RS, Olshan AF. Human papillomavirus and head and neck cancer: epidemiology and molecular biology. Head Neck. 1998;20:250-65.

27. Isaac A, Kostiuk M, Zhang H, Lindsay C, Makki F, O'Connell DA, et al. Ultrasensitive detection of oncogenic human papillomavirus in oropharyngeal tissue swabs. J Otolaryngol Head Neck Surg. 2017:46:5.

28. Biron VL, Kostiuk M, Isaac A, Puttagunta L, O'Connell DA, Harris J, et al. Detection of human papillomavirus type 16 in oropharyngeal squamous cell carcinoma using droplet digital polymerase chain reaction. Cancer. 2016;122:1544-51.

29. Thomas J, Primeaux T. Is p16 immunohistochemistry a more cost-effective method for identification of human papilloma virus-associated head and neck squamous cell carcinoma? Ann Diagn Pathol. 2012;16:91-9.

30. Licitra L, Perrone F, Bossi P, Suardi S, Mariani L, Artusi R, et al. High-Risk Human Papillomavirus Affects Prognosis in Patients With Surgically Treated Oropharyngeal Squamous Cell Carcinoma. J Clin Oncol. 2006;24:5630-6. Available from: http://eutils.ncbi.nlm.nih.gov/entrez/eutils/elink.fcgi?dbfrom= pubmed\&id $=17179101 \&$ retmode $=$ ref\&cmd=prlinks

31. Chung $\mathrm{CH}$, Zhang Q, Kong CS, Harris J, Fertig EJ, Harari PM, et al. p16 protein expression and human papillomavirus status as prognostic biomarkers of nonoropharyngeal head and neck squamous cell carcinoma. Proc Am Soc Clin Oncol. 2014;32:3930-8.

32. Xu CC, Biron VL, Puttagunta L, Seikaly H. HPV status and second primary tumours in oropharyngeal squamous cell carcinoma. J Otolaryngol Head Neck Surg. 2013;42:36.

33. King MT. The interpretation of scores from the EORTC quality of life questionnaire QLQ-C30. Qual Life Res. 1996;5:555-67.

34. Osoba D, Rodrigues G, Myles J, Zee B, Pater J. Interpreting the significance of changes in health-related quality-of-life scores. J Clin Oncol. 1998;16:139-44.

35. Fang F-M, Chien C-Y, Kuo S-C, Chiu H-C, Wang C-J. Changes in quality of life of head-and-neck cancer patients following postoperative radiotherapy. Acta Oncol. 2004:43:571-8.

36. Hirshoren N, Ruskin O, Fua T, Kleid S, Magarey M, Dixon B. Transoral robotic surgery: implementation as a tool in head and neck surgery - a singleCentre Australian experience. ANZ J Surg. 2016;86:80. Epub 2016/10/22

37. Broglie MA, Stoeckli SJ, Sauter R, Pasche P, Reinhard A, de Leval L, et al. Impact of human papillomavirus on outcome in patients with oropharyngeal cancer treated with primary surgery. Head Neck. 2017;22:88.

38. Dale OT, Han C, Burgess CA, Eves S, Harris CE, White PL, et al. Long-term functional outcomes in surgically treated patients with oropharyngeal cancer. Laryngoscope. 2015;125:1637-43.

39. Fakhry C, Andersen KK, Eisele DW, Gillison ML. Oropharyngeal cancer survivorship in Denmark, 1977-2012. Oral Oncol. 2015;51:982-4.

40. Patel MA, Blackford AL, Rettig EM, Richmon JD, Eisele DW, Fakhry C. Rising population of survivors of oral squamous cell cancer in the United States. Cancer. 2016;122:1380-7.

41. Larsen CG, Jensen DH, Carlander A-LF, Kiss K, Andersen L, Olsen CH, et al. Novel nomograms for survival and progression in HPV+ and HPVoropharyngeal cancer: a population-based study of 1,542 consecutive patients. Oncotarget. 2016;7:71761-72. 
42. Maxwell JH, Mehta V, Wang H, Cunningham D, Durvuri U, Kim S, et al. Quality of life in head and neck cancer patients: impact of HPV and primary treatment modality. Laryngoscope. 2014;124:1592-7.

43. Sharma A, Méndez E, Yueh B, Lohavanichbutr P, Houck J, Doody DR, et al. Human papillomavirus-positive oral cavity and oropharyngeal cancer patients do not have better quality-of-life trajectories. Otolaryngol Head Neck Surg. 2012;146:739-45.

44. Spinato G, Stellin M, Azzarello G, Bonazza D, Zanconati F, Politi D, et al. Multicenter research into the quality of life of patients with advanced oropharyngeal carcinoma with long-term survival associated with human papilloma virus. Oncol Lett. 2017;14:185-93.

45. Ringash J, Fisher R, Peters L, Trotti A, O'Sullivan B, Corry J, et al. Effect of p16 Status on the Quality-of-Life Experience During Chemoradiation for Locally Advanced Oropharyngeal Cancer: A Substudy of Randomized Trial TransTasman Radiation Oncology Group (TROG) 02.02 (HeadSTART). Int J Radiat Oncol Biol Phys. 2017;97:678-86.

46. Ling DC, Chapman BV, Kim J, Choby GW, Kabolizadeh P, Clump DA, et al. Oncologic outcomes and patient-reported quality of life in patients with oropharyngeal squamous cell carcinoma treated with definitive transoral robotic surgery versus definitive chemoradiation. Oral Oncol. 2016;61:41-6.

47. Broglie MA, Soltermann A, Haile SR, Röösli C, Huber GF, Schmid S, et al. Quality of life of oropharyngeal cancer patients with respect to treatment strategy and p16-positivity. Laryngoscope. 2013;123:164-70

Ready to submit your research? Choose BMC and benefit from:

- fast, convenient online submission

- thorough peer review by experienced researchers in your field

- rapid publication on acceptance

- support for research data, including large and complex data types

- gold Open Access which fosters wider collaboration and increased citations

- maximum visibility for your research: over $100 \mathrm{M}$ website views per year

At BMC, research is always in progress.

Learn more biomedcentral.com/submissions 